\title{
Ritalin Use Modifies Alcohol Effects in Rats
}

\author{
Blake R. Sonne, Nachum Dafny* \\ Department of Neurobiology and Anatomy, The University of Texas-Medical School at Houston, Houston, TX, \\ USA \\ Email: ${ }^{*}$ ndafny@uth.tmc.edu
}

Received 9 August 2014; revised 24 September 2014; accepted 9 October 2014

Copyright @ 2014 by authors and Scientific Research Publishing Inc.

This work is licensed under the Creative Commons Attribution International License (CC BY).

http://creativecommons.org/licenses/by/4.0/

(c) (i) Open Access

\section{Abstract}

Methylphenidate (MPD), known as Ritalin, is a common drug prescribed for those diagnosed with Attention Deficit Hyperactivity Disorder (ADHD).There are reports that many MPD users consume alcohol, resulting in toxic effects and hospitalization. The goal of this study was to investigate the effects of ethanol in rats concomitant with acute and repetitive MPD exposure. Rats were divided into four groups, control (saline), $0.6 \mathrm{mg} / \mathrm{kg} \mathrm{MPD,} 2.5 \mathrm{mg} / \mathrm{kg}$ MPD, and $10.0 \mathrm{mg} / \mathrm{kg}$ MPD groups and lasted for 12 consecutive days. Ethanol was given after repeated MPD administration as follows. On experimental day 1 (ED 1), all animals were treated with saline to establish baseline, on ED 2 through ED 7 either saline or MPD $(0.6,2.5$, or $10.0 \mathrm{mg} / \mathrm{kg})$ was given. On ED 11, after three days without treatment (ED 8 - 10), rats were treated as they were on ED 2 - 7. At ED 12, $1 \mathrm{~g} / \mathrm{kg}$ ethanol was administered, and one hour of locomotor activity was recorded after alcohol administration, using the open field assay. The data show a dose response characteristic of increased locomotor activity with increasing doses of MPD. Ethanol administration alone depresses locomotor activity. The depressive effect of alcohol was significantly attenuated in animals treated with MPD, in a dose dependent manner. The higher dose of MPD previously administered resulted in a larger attenuation of the ethanol's suppressive effect. These trends demonstrate that chronic MPD exposure directly influences the effects of alcohol in rats. Under these circumstances, it is reasonable to assume that a subject will need to consume an increased amount of ethanol in order to attain the ethanol effect desired. This discrepancy between effects and exposure may be a liability for ethanol toxicity.

\section{Keywords}

Methylphenidate, Ethanol, Behavior, Sensitization, Tolerance, Drug Interaction

\footnotetext{
${ }^{*}$ Corresponding author.
} 


\section{Introduction}

Methylphenidate (MPD, or Ritalin) is a prescription medication used for the treatment of Attention Deficit Hyperactivity Disorder (ADHD). This drug is a stimulant and shares similar neurophysiological mechanisms with cocaine and amphetamine [1]-[6]. A review that includes over 110,000 subjects reported that $5 \%$ to $35 \%$ of 18 - 22-year-old individuals misuse non-prescribed stimulant medication [7]. A recent survey reports that $92 \%$ of adult ADHD patients use ethanol while under the influence of prescribed MPD. This survey also includes that all individuals who illegally use MPD through diversion co-abuse ethanol as well [8]. Many MPD users use alcohol, in fact, particularly in college settings [9]. It is postulated that alcohol consumption following MPD use could have a liability outcome. A study of 10,900 college students reports that non-medical use of stimulants increases the chance of alcohol use, possibly leading to high-risk behavior [9]. Public awareness of college binge drinking has increased over the past decade, as alcohol use has been associated with the leading causes of death in young adults [10]. Alcohol dependence predisposes individuals to becoming non-medically stimulant dependant [11]. A prior study in humans concluded that subjects who take MPD while under the influence of alcohol claim to experience increased euphoria and dynamism accompanied by feelings of decreased intoxication by alcohol [12] [13]. This may also play a role in the amount of alcohol consumed by the subject. These patterns warrant the further investigation of the interactions between alcohol and chronic MPD users. The open field assay was used in this study with an animal model to access the changes in animal behavioral activity before and upon ethanol administration subsequent to the chronic MPD dose response protocol [14]-[20]. Ascertaining whether there is a liability interaction between these two commonly used psychoactive drugs will help both health care providers and the public.

\section{Materials and Methods}

\subsection{Subjects}

Thirty-four Sprague-Dawley (SD) male rats (Harlan, Indianapolis, IN) were purchased 60 days after birth and housed 3 per cage for acclimation in a sound-attenuated experiment room for 3 - 4 days. Rats weighed approximately 185 grams at the initiation of the experiment. No physical contact occurred between rats receiving different dosages of MPD to avoid possible behavioral transfer. Rats were maintained on a 12/12 hour light/dark cycle (lights off at 18:00, on at 6:00 hrs). The habitat temperature was kept at $21^{\circ} \mathrm{C} \pm 1{ }^{\circ} \mathrm{C}$, with a relative humidity of $61 \% \pm 2 \%$. Food and water were administered ad libitum.

\subsection{Apparatus}

The open field assay consists of a clear acrylic cage $(40.5 \mathrm{~cm} \times 40.5 \mathrm{~cm} \times 31.5 \mathrm{~cm})$ with two levels of 16 infrared beams and their sensors, each mounted at $6 \mathrm{~cm}$ and $12.5 \mathrm{~cm}$ above the bottom of each cage (AccuScan Instruments Inc., Columbus, $\mathrm{OH}$ ). The experimental cages are connected to an AccuScan analyzer, which is connected to a personal computer (PC) for data analysis. The infrared beam interruptions by the animal movement are counted by the AccuScan analyzer, summed into ten-minute bins, and downloaded to the PC. OASIS program is used to process the signals into movement pattern indices. The three locomotor indices that were analyzed are as follows: horizontal activity, total distance, and number of stereotypic movements. Horizontal activity (HA) is a record of the total number of beam interruptions that occur at the horizontal sensors. It represents the rat's overall locomotor activity recorded in a given period of time. Total distance (TD) is the measurement of the rat's forward ambulation movement in centimeters. Number of stereotypic movements (NOS) is the measurement of the animal's purposeless repetitive movement, with at least a one second interval between beam breaking, which is used to assess the stereotypic behavior triggered by the treatment.

\subsection{Drugs}

Methylphenidate (Mallinckrodt Inc., St. Louis, MO, USA) was dissolved in $0.9 \%$ isotonic saline solution to create the three proposed dosages of $(0.6,2.5$, and $10.0 \mathrm{mg} / \mathrm{ml})$. The dosages $0.6,2.5$, and $10.0 \mathrm{mg} / \mathrm{kg}$ MPD (i.p.), are calculated as freebase. Dosages were selected from prior MPD dose response studies [6] [14]-[19] [21]. These studies assessed the dose responses of eight different concentrations of MPD, in which three were selected. These concentrations refer to a low, moderate, and high dose of MPD, respectively [19]. All injections were administered intraperitoneally (i.p.) in a volume of $0.8 \mathrm{ml}$. Ethanol was administered at the dosage of 1 
$\mathrm{g} / \mathrm{kg}$ [22] and was diluted to $0.8 \mathrm{ml}$ with $0.9 \%$ isotonic saline solution to ensure that the total volume of each injection would not vary from animal to animal. All injections were given between 11:00 and 14:00 hours.

\subsection{Experimental Protocol}

The thirty-four SD male rats were randomly assigned to following groups: control (saline), $0.6 \mathrm{mg} / \mathrm{kg}, 2.5$ $\mathrm{mg} / \mathrm{kg}$, and $10 \mathrm{mg} / \mathrm{kg}$ MPD. The study duration consisted of twelve consecutive experimental days (EDs) (Table 1). Recording sessions took place for 60 minutes. Rats were acclimated to experimental cages for 20 - 30 minutes prior to each recording day. ED 1 is a baseline recording. From ED 2 to ED 7, each group (saline, 0.6, 2.5, and $10.0 \mathrm{mg} / \mathrm{kg}$ MPD) was treated with their respective treatments (Table 1), followed by three washout (WO) days (ED 8, 9, and 10), during which no injection was given. On ED 11, rats received the same treatment that was administered during ED2 to ED 7. On ED 12, all animals were treated with $1 \mathrm{~g} / \mathrm{kg}$ ethanol (Table 1). All recordings were initiated immediately after injections.

\subsection{Data Analysis}

The locomotor activity counts were summed into six 10-minute bins. These recordings were used for two types of data evaluation. A sequential temporal graph shows the latency, duration, and peak effect of the treatment. The sixty-minute sum of the activity under the respective temporal data was applied to a histogram. Several comparisons were made. The animal's movement on experimental day 2 (ED 2) with the first MPD administration was compared to the animal's baseline movement on ED 1 to obtain the acute effect of MPD. The locomotor activity on ED 2 (after the first MPD administration) was compared to the locomotor activity on ED 7 (after the sixth MPD administration) to find out whether MPD treatment induced sensitization. The comparison of activity on ED 11 post MPD exposure with the activity on ED 2 post initial MPD exposure was to determine the effect of MPD at the expression phase and find out whether behavioral sensitization was established [20] [23]. Since chronic MPD exposure can elicit behavioral sensitization [16] [18] [20] [24] [25]. The locomotor differences between ED 1 (baseline) and ED 12 (after ethanol administration) were used for ethanol control (Table 1). This was done to observe the effect of ethanol alone, as well as to compare with the other groups to obtain the effect of ethanol in animals treated chronically with MPD [20]. One-way analysis of variance (ANOVA) and posthoc Fischer's L.S.D. method ( $<<0.05$ ) was used to obtain significant differences compared to control.

\section{Results}

\subsection{Control}

Figure 1 summarizes the horizontal activity (HA) of the saline (control) group and exhibit similar total activity among these eleven days with minor non-significant fluctuation. Previous studies [15]-[20] [25]-[27] using identical protocol reported minor, insignificant fluctuations in the behavioral and electrophysiological study of rats injected with saline vs. rats that received no injection. The above studies have shown that time (42 days) and repetitive saline injections (42 days) exhibit similar activity with minor and insignificant fluctuations [15] [16] [19]. This permits the use of saline injection at ED 1 as a control for the drug effect (injections ( $0.8 \mathrm{ml})$ and handling of the animals.

Table 1. Describes the experimental protocol for the 4 rat groups.

\begin{tabular}{ccccccc}
\hline & & \multicolumn{5}{c}{ Experimental protocol } \\
\hline & $\mathrm{n}$ & ED 1 & ED 2-7 & ED 8-10 & ED 11 & ED 12 \\
\hline Saline (control) & $\mathrm{n}=7$ & saline & saline & wash-out & saline & ethanol \\
$0.6 \mathrm{mg} / \mathrm{kg} \mathrm{MPD}$ & $\mathrm{n}=8$ & saline & MPD & wash-out & MPD & ethanol \\
$2.5 \mathrm{mg} / \mathrm{kg} \mathrm{MPD}$ & $\mathrm{n}=11$ & saline & MPD & wash-out & MPD & ethanol \\
$10.0 \mathrm{mg} / \mathrm{kg}$ MPD & $\mathrm{n}=8$ & saline & MPD & wash-out & MPD & ethanol \\
\hline
\end{tabular}

$\mathrm{ED}=$ experimental day, MPD = methylphenidate; No injection was given on wash-out days. The MPD dosage administered on ED 11 was the same dosage administered on EDs 2 - 7. Ethanol was administered at the dosage of $1 \mathrm{~g} / \mathrm{kg}$. All injections were intra-peritoneal. 


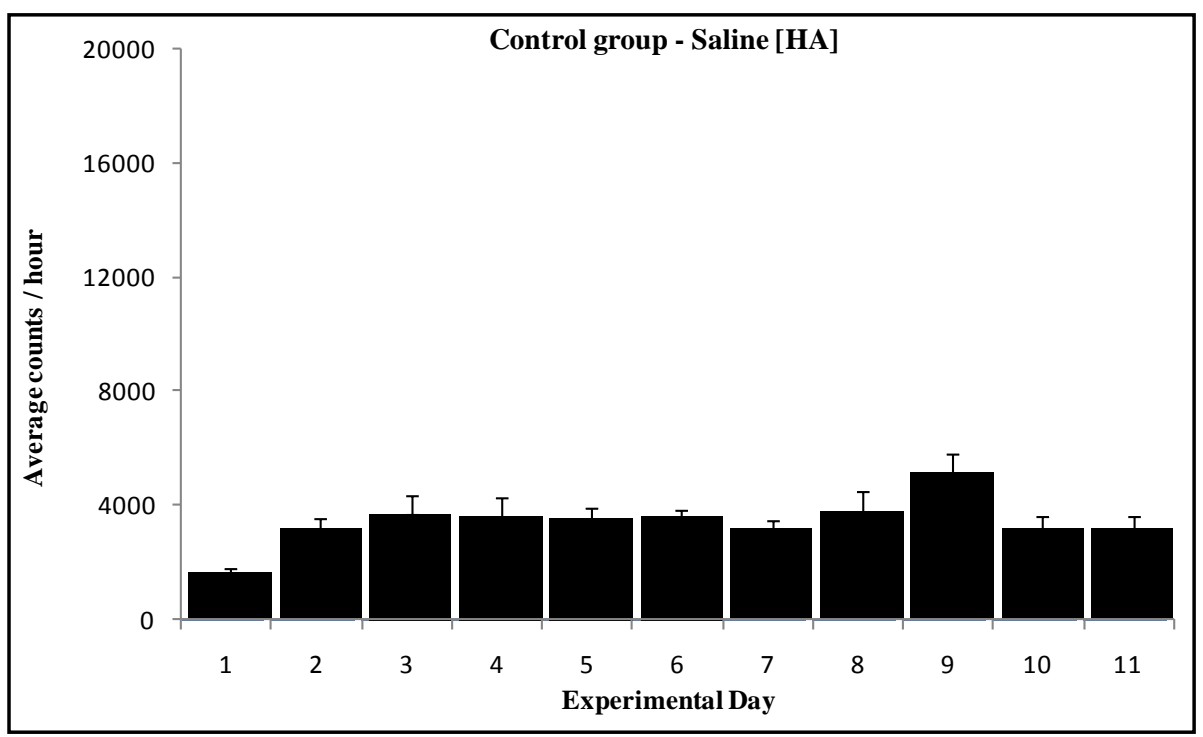

Figure 1. Summarizes eleven consecutive days of the horizontal activity recorded (1 hour) following saline injection.

\subsection{Dose Response Characteristics Following Acute MPD Administration (Comparing ED 2 vs. ED 1)}

The dose response characteristics of acute MPD administration in all three locomotor indices are summarized in Figure 2. The administration of $0.6 \mathrm{mg} / \mathrm{kg}$ MPD failed to alter the locomotor activity, while the $2.5 \mathrm{mg} / \mathrm{kg}$ MPD elicited significant $(\mathrm{p}<0.05, \mathrm{f}=15.29)$ increases of activity in the TD traveled (Figure 2, TD). Subjects receiving $10.0 \mathrm{mg} / \mathrm{kg}$ MPD showed significant $(\mathrm{p}<0.05$ ) increases in activity (Figure 2) across all three locomotor indices (HA; $f=35.89$, TD; $f=29.26$, NOS; $f=28.09$ ). Temporal analysis of the acute effect demonstrated that MPD had its largest effect between 20 - 30 minutes post MPD injection. The stimulating effects of MPD began to diminish between 50 - 60 minutes post injection (data not shown).

\subsection{Dose Response Characteristics of MPD at the Induction Phase (Comparing ED 7 vs. ED 2)}

The dose response characteristics of chronic MPD administration are shown in Figure 2. The $0.6 \mathrm{mg} / \mathrm{kg}$ MPD group showed significant $\left({ }^{\ddagger} \mathrm{p}<0.05, \mathrm{f}=2.42\right)$ increases in ED 7 post MPD exposure compared to ED 2 post MPD exposure only in the NOS activity. Subjects receiving $2.5 \mathrm{mg} / \mathrm{kg}$ MPD showed significant $\left.{ }^{\ddagger} \mathrm{p}<0.05\right)$ increases in activity on ED 7, as compared to ED 2, across all locomotor indices (HA; $f=18.92$, TD; $f=15.29$, NOS; $f=21.68$ ). The $10.0 \mathrm{mg} / \mathrm{kg}$ MPD dosage group showed increased activity in all groups but only the HA locomotor index exhibited significant $\left({ }^{\ddagger} \mathrm{p}<0.05, \mathrm{f}=35.89\right)$ increases in activity on ED 7, compared to ED 2 (Figure 2). These further increases in HA in ED 7 compared to ED 2 indicate that behavioral sensitization to MPD was induced. The majority of the increases of activity took place 20 - 40 minutes post injection.

\subsection{Dose Response Characteristics of MPD at the Expression Phase (Comparing ED 11 vs. ED 2)}

The dose response characteristics of chronic MPD administration are shown in Figure 2. The expression phase is the comparison of the MPD re-challenge at ED 11, which follows six daily MPD treatments and three washout days, to the activity obtained following the first MPD administration (ED 2), i.e., ED $11 \mathrm{vs.} \mathrm{ED} 2.0 .6 \mathrm{mg} / \mathrm{kg}$ MPD administration at ED 11 compared to ED 2 fails to alter locomotion while the $2.5 \mathrm{mg} / \mathrm{kg}$ elicits increases of activity in all three locomotor indices. Only the NOS index exhibits further significant $(p<0.05 ; \mathrm{f}=2.42)$ increases in their activity following the administration of MPD. The $10.0 \mathrm{mg} / \mathrm{kg}$ MPD groups also exhibit increases in the HA and TD indices, but only the HA shows significant $\left({ }^{*} \mathrm{p}<0.05, \mathrm{f}=35.89\right)$ increases in activity. However the NOS activity on ED 11 is lower than that of ED 2 (the initial MPD administration). 

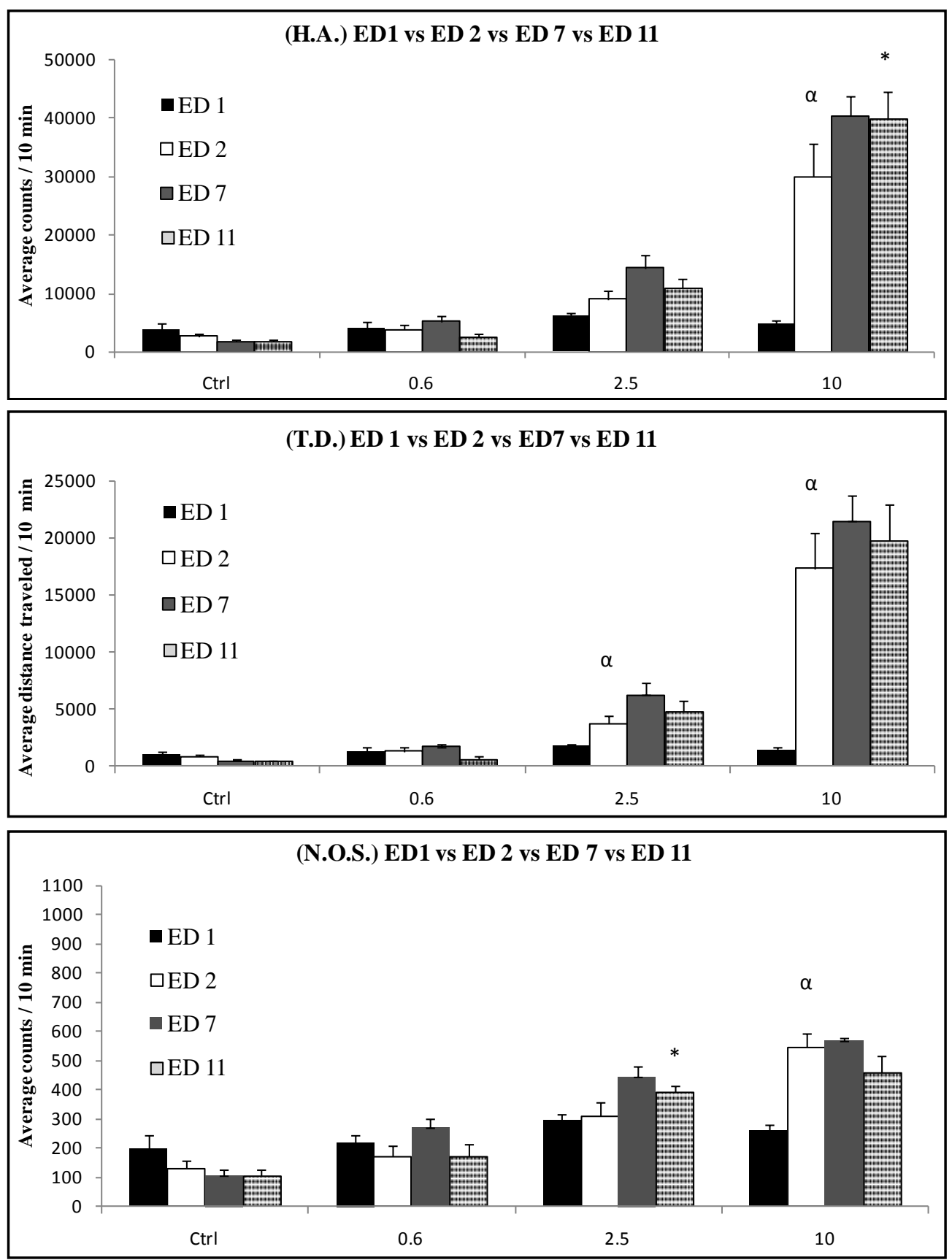

Figure 2. Summarizes the differences in locomotor activity for horizontal activity (HA), total distance (TD), and number of stereotypic (NOS) movements between experimental day 1 (ED 1) (baseline, saline administration), ED 2 (first methylphenidate (MPD) administration), ED 7 (6th MPD administration), and ED 11 (MPD re-challenge). Ctrl-activity following saline injection of the saline control group; At ED 1 all groups were treated with saline; 0.6, 2.5, and 10.0 indicates the dose of MPD in $\mathrm{mg} / \mathrm{kg}$. Symbols indicate significant differences $(\mathrm{p}<0.05)$ as follows: $\alpha=\mathrm{ED} 2 \mathrm{vs}$. ED $1 ;^{\ddagger}=\mathrm{ED} 7 \mathrm{vs}$. ED 2; ${ }^{*}=$ ED 11 vs. 2.

\subsection{Response Characteristics of Ethanol Alone and After Chronic Methylphenidate Administration}

Changes in locomotor activity following ethanol administration in MPD naïve animals and in animals previously exposed to methylphenidate (Table 1) are summarized in Figure 3 and Table 2. Ethanol administration 

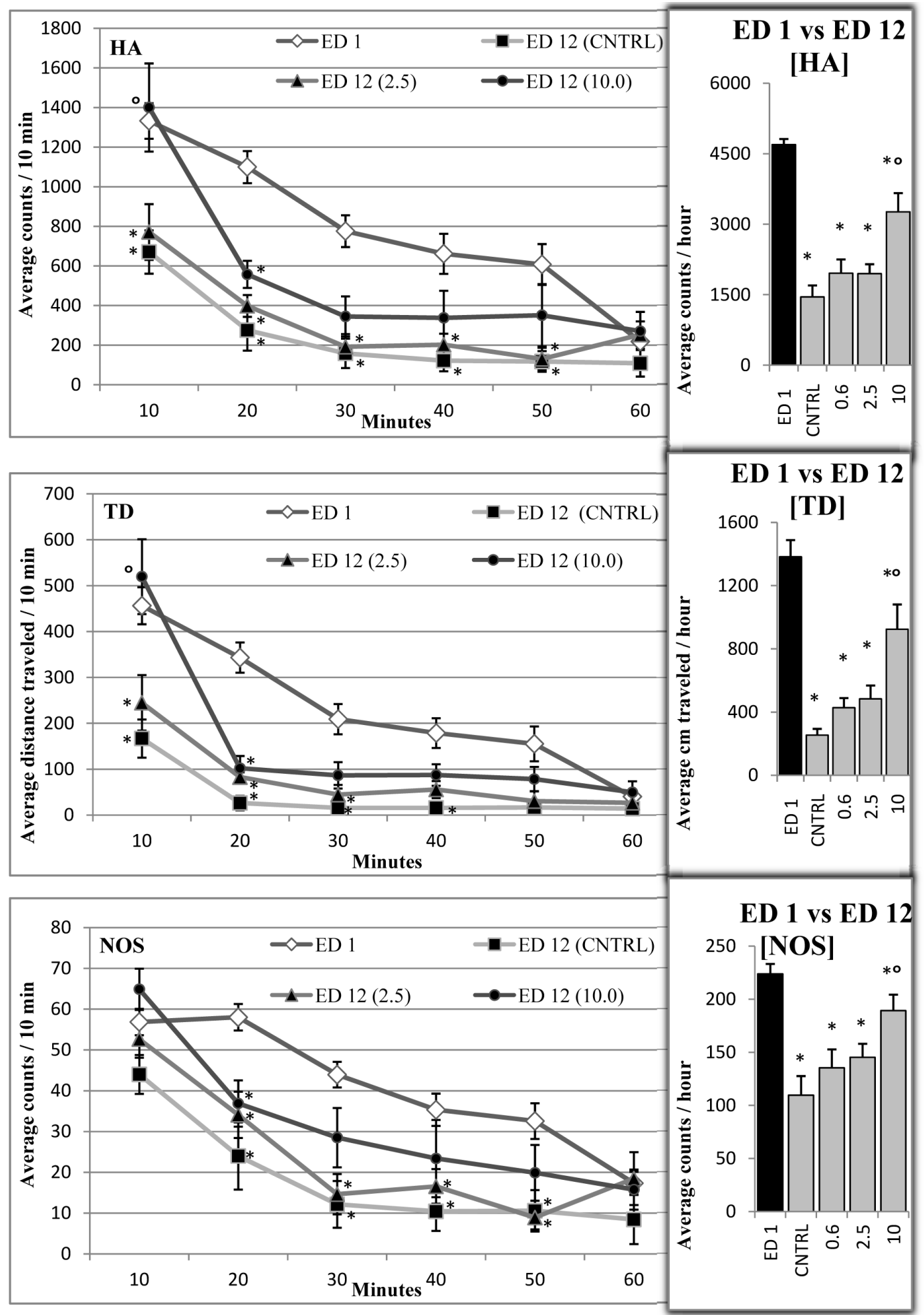

Figure 3. summarizes the differences in locomotor activity for HA, TD, and NOS between ED 1 (baseline, saline administration)and ED 12 where control, 0.6, 2.5, and $10.0 \mathrm{mg} / \mathrm{kg}$ methylphenidate groups received ethanol. ED 1-Activity following saline injection; CNTRL-activity following ethanol (EtOH) administration; 0.6, 2.5, and 10.0 show the effect of EtOH in animals chronically treated with $0.6,2.5$, and $10.0 \mathrm{mg} / \mathrm{kg}$ MPD. Symbols indicate significant differences as follows: ○ Comparing EtOH control (ED 12) to EtOH in MPD treated animals; * Comparing to saline control (ED 1). 
Table 2. Provides two types of comparison between the experimental groups.

\begin{tabular}{|c|c|c|c|}
\hline & & A. $\%$ decrease from & $\begin{array}{l}\text { B. \% increase } \\
\text { from control's }\end{array}$ \\
\hline & & baseline movement & alcohol response \\
\hline \multirow{4}{*}{ HA } & control & $69.0 \%$ & N/A \\
\hline & 0.6 mg/kg MPD & $58.4 \%$ & $34.7 \%$ \\
\hline & $2.5 \mathrm{mg} / \mathrm{kg}$ MPD & $58.5 \%$ & $33.9 \%$ \\
\hline & $10.0 \mathrm{mg} / \mathrm{kg}$ MPD & $30.5 \%$ & $124.6 \%$ \\
\hline \multirow{3}{*}{ TD } & control & $81.6 \%$ & N/A \\
\hline & 0.6 mg/kg MPD & $69.1 \%$ & $68.3 \%$ \\
\hline & 2.5 mg/kg MPD & $64.9 \%$ & $90.2 \%$ \\
\hline \multirow{5}{*}{ NOS } & $10.0 \mathrm{mg} / \mathrm{kg}$ MPD & $33.2 \%$ & $263.0 \%$ \\
\hline & control & $51.0 \%$ & N/A \\
\hline & 0.6 mg/kg MPD & $39.5 \%$ & $23.5 \%$ \\
\hline & 2.5 mg/kg MPD & $35.1 \%$ & $32.5 \%$ \\
\hline & $10.0 \mathrm{mg} / \mathrm{kg}$ MPD & $15.4 \%$ & $72.7 \%$ \\
\hline
\end{tabular}

(A) shows the percent decreases in HA, TD, and NOS activity between ED1 (baseline) and recordings on ED 12 following ethanol administration (control, 0.6, 2.5, and $10.0 \mathrm{mg} / \mathrm{kg}$ MPD). (B) shows the percent increases in locomotor activity between the control's alcohol response (ED 12) and the alcohol responses (ED 12) for subjects receiving MPD treatment.

$(1 \mathrm{~g} / \mathrm{kg}$, ED 12 [CNTRL]) elicited significant ( $\mathrm{p}<0.05, \mathrm{f}=16.64$ (HA), $\mathrm{f}=12.44$ (TD), $\mathrm{f}=11.85$ (NOS)) suppression of the locomotor activity compared to activity following saline (control). When the same dose of ethanol was given to the MPD treated rats at ED 12 and compared to the ethanol control group, the suppressive effect of alcohol was attenuated in a dose response characteristic across all the locomotor indices for the $0.6 \mathrm{mg} / \mathrm{kg}$ MPD, $2.5 \mathrm{mg} / \mathrm{kg}$ MPD, and $10.0 \mathrm{mg} / \mathrm{kg}$ MPD groups (Figure 3). The ten-minute sequential temporal graphs (Figure 3) show that ethanol exerts optimal effects at twenty minutes post-administration. The data show that when ethanol is administered in addition to a higher dose of chronically administered MPD (10 mg/kg), the suppressive effect of alcohol is significantly more attenuated ( $p<0.05, f=0.0014$ (HA), $f=0.0066$ (TD), $f=$ 0.0152 (NOS)) in comparison to the other doses ( 0.6 and $2.5 \mathrm{mg} / \mathrm{kg}$ ). Thus, the suppressive effect of the alcohol on locomotor activity was decreased with increasing doses of methylphenidate (Table 2 and Figure 3). Table 2(A) shows the degree of the change in percent decrease of locomotor activity between ED1 (baseline) and recordings on ED 12 following ethanol administration for the four animal groups (control, 0.6, 2.5, and 10.0 $\mathrm{mg} / \mathrm{kg}$ MPD). There are decreases in the percent suppression by alcohol. This suppression effect was dose related, i.e., with increasing doses of MPD, the suppression effect of alcohol decreases. Table 2(B) shows the percent increase in locomotor activity between the control's alcohol response (ED 12) and the alcohol responses (ED 12) for subjects receiving MPD treatment. The table demonstrates that the higher doses of MPD treated animals are correlated with the degree/percentage of the alcohol's suppressive response. Differences in the percent suppression of movement between the subjects that received $2.5 \mathrm{mg} / \mathrm{kg}$ MPD and the subjects that received $10.0 \mathrm{mg} / \mathrm{kg}$ MPD (ED 1 vs. ED 12) are as follows: $\mathrm{HA}=28 \%, \mathrm{TD}=31.7 \%$, NOS $=19.7 \%$.

\section{Discussion}

Methylphenidate (MPD) is the most commonly prescribed medication for the treatment of ADHD [1] [3] [8] [11] [25] [28] [29] and shares similar chemical structure and properties with cocaine and amphetamine [6] [7] [30][34], which are well known drugs of abuse. It has been shown that methylphenidate (MPD) is abused by its users [35]. The use of MPD by those with ADHD, its illicit use to enhance academic performance, and its more recent recreational misuse necessitate the investigation of MPD's interactions with other common recreational drugs. There are controversial reports as to whether MPD treatment has the potential to elicit drug dependence to other psychostimulants [35] [36]. Those affected by ADHD who are treated with psychostimulants have a greater potential to become drug abusers [25].

The objective of this study was to investigate the behavioral response to a single alcohol administration in animals treated chronically with different doses of MPD. The acute dose response for the 2.5 and $10.0 \mathrm{mg} / \mathrm{kg}$ 
MPD groups (moderate and high MPD doses [8]) shows increases in locomotor activity in comparison to their baseline recordings (Figure 2). This is expected: prior MPD dose response experiments have shown similar results [16]-[21] [25] [37], indicating that chronic MPD administration elicits persistent changes in the CNS [38] [39].

The present study shows that ethanol administration to the control group resulted in decreases in locomotor activity compared to baseline locomotor activity by $69 \%, 81 \%$ and $51 \%$ of the HA, TD, and NOS indices respectively (Table 2(A)). Ethanol given to MPD treated animals modulates ethanol's suppressive effects. MPD treated animals that were administered ethanol exhibit less locomotor suppression, compared to the MPD naïve animals that were administered ethanol. With increasing doses of MPD (previously administered), the suppressive effect of alcohol on locomotor activity is decreased. There is a large decrease in the suppressive effects of ethanol between groups receiving 2.5 and $10 \mathrm{mg} / \mathrm{kg}$ ethanol (Table 2). Subjects receiving $10.0 \mathrm{mg} / \mathrm{kg}$ MPD experienced a major decrease in the suppressive effect of ethanol. The values on Table 2 suggest that MPD users who take high doses of MPD are much more susceptible to the attenuation of the suppressive effects of alcohol compared to users that take low or moderate doses of MPD. This also suggests that MPD users that take high doses of MPD and have the desire to enjoy the alcohol's effect may need to drink more alcohol to obtain the desired effects. A reasonable example includes the college student who uses methylphenidate to study for an exam as a cognitive enhancing agent and then following the exam, will celebrate this event partying with alcohol consumption.

Many MPD users use alcohol, particularly in college settings [9]. A study of 10,900 college students reported that non-medical use of stimulants increases alcohol use, possibly leading to high-risk behavior [9]. Additionally, alcohol has been shown to be associated with the leading causes of death in young adults [10], and alcohol dependence predisposes individuals to becoming dependent on non-medical stimulants [11]. Subjects who have co-administered MPD and ethanol have reported decreased feelings of the alcohol's effects as compared to when ethanol is consumed individually [40], resulting in increased ethanol consumption compared to when ethanol is taken alone [32]. Additionally, adolescent spontaneously hyperactive rats (SHR) the animal model for ADHD, when chronically treated with MPD have shown increased alcohol drinking upon the adult stage [41]. Others report that this increased alcohol consumption does not occur [42]. Methylphenidate is a dopamine transporter blocker (also a less potent norepinephrine transporter blocker) and thus increases the amount of dopamine within the synaptic cleft [20] [43]. This prolongs the rewarding effects of dopamine. Dopamine levels were found to be $50 \%-70 \%$ lower in the ventral striatum and putamen of alcoholics as compared to control non-alcoholics [44]. This suggests that alcoholics who use MPD may need to consume more alcohol to experience the same desired effect as non-MPD users. A previous study in humans concluded that subjects who took MPD while under the influence of alcohol claimed to experience increased euphoria and dynamism, accompanied by feelings of decreased intoxication by alcohol [4]. This may also play a role in the amount of alcohol consumed by the subject.

There are numerous scenarios in which complications may occur following the co-administration of these two drugs. Concomitant ethanol administration has been shown to potentiate the stimulatory effects of methylphenidate on locomotor activity in mice [40]. It has been shown that co-administration of ethanol and MPD increases plasma MPD concentrations in comparison to when MPD is administered alone [13] [32] [38]. The formation of the metabolite ethylphenidate has been shown to occur in response to the co-administration of ethanol and MPD [45]. The metabolite ethylphenidate given alone elicits increased locomotor activity in a dose response characteristic, albeit less intensely than methylphenidate [46]. Upon MPD/ethanol co-administration in mice, wholebrain concentrations of ethylphenidate were found to be higher in comparison to when methylphenidate was given alone. In comparison to MPD, ethylphenidate blocks the norepinephrine transporter less potently [46]. These findings could indicate that there is an imbalance of the interactions which occur between the noradrenergic and the dopaminergic systems within the brain [46]. Methylphenidate administration alone increases locomotor activity. Ethanol administration alone decreases locomotor activity. The effects of these drugs are diminished when administered concomitantly. This may take place as a result of direct drug-drug interaction and ethylphenidate's alteration of the noradrenergic and dopaminergic system balance. Examination of the interactions between alcohol and MPD showed that acute alcohol exposure inhibited the activation of NMDA receptors by diminishing the excitatory action of glutamate [47]. Studies in rats have shown that glutaminergic afferents from the prefrontal cortex (PFC) modulate the dopaminergic activity in the ventral tegmental area (VTA) and the nucleus accumbens (NAc) [48]-[52]. The VTA and NAc are regions involved in the phenomenon of behavioral sensitization of psychostimulants [53]. Additionally, the PFC glutaminergic afferents activate NMDA re- 
ceptors in VTA dopaminergic neurons, which are partially responsible for the induction of behavioral sensitization [54]. These PFC glutaminergic afferents are necessary for the expression of the acute and chronic effects of MPD [55]. Hence, the inhibition of glutamate's excitatory action by alcohol may possibly influence the augmentation of dopamine levels in the VTA and NAc by MPD. Zhang et al. [27] reported that MPDs enhance the NMDA mediated $\sigma_{1}$ receptor activation in the PFC. Antagonism of $\sigma_{1}$ receptors decreased ethanol-seeking behavior in the animal model. $\sigma_{1}$ receptors are located in the PFC, VTA, and NAc, CNS sites where psychostimulants exert their effects [56]. Another prospective interaction between MPD and ethanol may include kainite receptors. Chronic MPD administration has been shown to upregulate kainite-2 receptors in the ventral striatum [57]. It has been shown that pre-synaptic kainite receptors increase GABA ergic neurotransmission in rat periaqueductal gray neurons [5]. Ethanol's mechanism of action includes the augmentation of GABA levels [58]. These findings imply that chronic MPD administration can intensify the effects of GABA upon ethanol administration. In addition, it has been show that NMDA and kainate receptors exist not only within the synapse, but at extrasynaptic locations. This may allow for further interactions beyond the neuronal synapse, broadening the interactions between MPD and ethanol [59].

\section{Conclusion}

Both students diagnosed with ADHD and treated daily with MPD and students who utilize MPD for cognitive enhancement to improve their academic performance consume MPD prior to periods of exams. After the exam, many of them celebrate the occasion with alcohol consumption, some of whom must then be taken to the emergency room for toxicity. This experiment can explain at least in part why this occurs. The use of MPD attenuates the effects of the alcohol. To obtain the desired pleasure from alcohol, students must increase the dose of alcohol consumption. Once they increase the dose of alcohol, they find themselves in the emergency room. Ascertaining the extent of the interactions between MPD and alcohol will both promote awareness and aid healthcare providers in treating the aforementioned students.

\section{Acknowledgements}

The authors of this paper would like to thank Ms. Sheshali Wanchoo and Dr. Mircea Chelaru for their assistance in this experiment, for editing Heather Kregel as well as the partial support of NIH R01-DA027222 grant. We wish to thank Mallinkrodt Inc. for the gift of methylphenidate.

\section{References}

[1] Askenasy, E.P., Taber, K.H., Yang, P.B. and Dafny, N. (2007) Methylphenidate (Ritalin): Behavioral Studies in the Rat. International Journal of Neuroscience, 117, 757-794.

[2] Biederman, J., Faraone, S.V., Mick, E., Milberger, S., Spencer, T.J. and Wilens, T. (1995) Psychoactive Substance Use Disorders in Adults with Attention Deficit Hyperactivity Disorder (ADHD): Effects of ADHD and Psychiatric Comorbidity. American Journal of Psychiatry, 152, 1652-1658.

[3] Crutchley, A. and Temlett, J.A. (1999) Methylphenidate (Ritalin) Use and Abuse. South African Medical Journal, 89, 1076-1079. http://dx.doi.org/10.1200/JCO.2007.12.7837

[4] McCance-Katz, E.F., Kosten, T.R. and Jatlow, P. (1998) Concurrent Use of Cocaine and Alcohol Is More Potent and Potentially More Toxic than Use of Either Alone-A Multiple-Dose Study. Biological Psychiatry, 44, 250-259. http://dx.doi.org/10.1634/theoncologist.2010-0190

[5] Nakamura, M. and Jang, I.S. (2010) Presynaptic Nicotinic Acetylcholine Receptors Enhance GABAergic Synaptic Transmission in Rat Periaqueductal Gray Neurons. European Journal of Pharmacology, 640, 178-184. http://dx.doi.org/10.1056/NEJMoa1003466

[6] Teo, S.K. Stirling, D.I., Hoberman, A.M., Christian, M.S., Thomas, S.D. and Khetani, V.D. (2003) D-Methylphenidate and D,L-Methylphenidate Are Not Developmental Toxicants in Rats and Rabbits. Birth Defects Research and Brain Development Reproductive Toxicology, 68, 162-171. http://dx.doi.org/10.1056/NEJMoa1104621

[7] Wilens, T.E., Adler, L.A., Adams, J., Sgambati, S., Rotrosen, J., Sawtelle, R., Utzinger, L. and Fusillo, S. (2008) Misuse and Diversion of Stimulants Prescribed for ADHD: A Systematic Review of the Literature. Journal of the American Academy of Child and Adolescent Psychiatry, 47, 21-31. http://dx.doi.org/10.1056/NEJMoa1103782

[8] Darredeau, C., Barrett, S.P., et al. (2007) Patterns and Predictors of Medication Compliance, Diversion, and Misuse in Adult Prescribed Methylphenidate Users. Human Psychopharmacology, 22, 529-536. 
http://dx.doi.org/10.1200/JCO.2012.41.6750

[9] McCabe, S.E., Knight, J.R., Teter, C.J. and Wechsler, H. (2005) Non-Medical Use of Prescription Stimulants among US College Students: Prevalence and Correlates from a National Survey. Addiction, 100, 96-106. http://dx.doi.org/10.1007/s10637-009-9376-8

[10] Boyd, C.J., Morales, S.E. and McCabe, M. (2012) College Students’ Alcohol Use: A Critical Review. Annual Review of Nursing Research, 23, 179-211. http://dx.doi.org/10.1186/1479-5876-9-204

[11] O’Brien, M.S. and Anthony, J.C. (2009) Extra-Medical Stimulant Dependence among Recent Initiates. Drug and Alcohol Dependence, 104, 147-155. http://dx.doi.org/10.1016/j.drugalcdep.2009.04.016

[12] Barrett, S.P. and Pihl, R.O. (2002) Oral Methylphenidate-Alcohol Co-Abuse. Journal of Clinical Psychopharmacology, 22, 633-634. http://dx.doi.org/10.1097/00004714-200212000-00020

[13] Patrick, K.S., Straughn, A.B., Minhinnett, R.R., Yeatts, S.D., Herrin, A.E., DeVane, C.L., Malcolm, R., Janis, G.C. and Markowitz, J.S. (2007) Influence of Ethanol and Gender on Methylphenidate Pharmacokinetics and Pharmacodynamics. Clinical Pharmacology and Therapeutics, 81, 346-353. http://dx.doi.org/10.1038/sj.clpt.6100082

[14] Gaytan, O., Ghelani, D., Martin, S., Swann, A. and Dafny, N. (1996) Dose Response Characteristics of Methylphenidate on Different Indices of Rats' Locomotor Activity at the Beginning of the Dark Cycle. Brain Research, 727, $13-21$. http://dx.doi.org/10.1016/0006-8993(96)00296-X

[15] Gaytan, O., Ghelani, D., Martin, S., Swann, A. and Dafny, N. (1997) Methylphenidate: Diurnal Effects on Locomotor and Stereotypic Behavior in the Rat. Brain Research, 777, 1-12. http://dx.doi.org/10.1016/S0006-8993(97)00880-9

[16] Gaytan, O., Al-Rahim, S., Swann, A. and Dafny, N. (1997) Sensitization to Locomotor Effects of Methylphenidate in the Rat. Life Sciences, 61, 101-107. http://dx.doi.org/10.1016/S0024-3205(97)00598-5

[17] Gaytan, O., Swann, A., Yang, P. and Dafny, N. (2000) Diurnal Differences in Sensitization to Methylphenidate. Brain Research, 864, 24-39. http://dx.doi.org/10.1016/S0006-8993(00)02117-X

[18] Yang, P.B., Amini, B., Swann, A.C. and Dafny, N. (2003) Strain Differences in the Behavioral Responses of Male Rats to Chronically Administered Methylphenidate. Brain Research, 971, 139-152. http://dx.doi.org/10.1016/S0006-8993(02)04240-3

[19] Yang, P.B., Swann, A.C. and Dafny, N. (2006) Acute and Chronic Methylphenidate Dose-Response Assessment on Three Adolescent Male Rat Strains. Brain Research Bulletin, 71, 301-310. http://dx.doi.org/10.1016/j.brainresbull.2006.09.019

[20] Yang, P.B., Swann, A.C. and Dafny, N. (2007) Chronic Administration of Methylphenidate Produces Neurophysiological and Behavioral Sensitization. Brain Research, 1145, 66-80. http://dx.doi.org/10.1016/j.brainres.2007.01.108

[21] Yang, P.B., Swann, A.C. and Dafny, N. (2006) Dose-Response Characteristics of Methylphenidate on Locomotor Behavior and on Sensory Evoked Potentials Recorded from the VTA, NAc, and PFC in Freely Behaving Rats. Behavioral and Brain Function, 2, 3. http://dx.doi.org/10.1186/1744-9081-2-3

[22] Hoshaw, B.A. and Lewis, M.J. (2001) Behavioral Sensitization to Ethanol in Rats: Evidence from the Sprague-Dawley Strain. Pharmacology Biochemistry and Behavior, 68, 685-690. http://dx.doi.org/10.1016/S0091-3057(01)00489-0

[23] Algahim, M.F., Burau, K.D., Dafny, N., Swann, A.C., Wilcox, V.T., and Yang, P.B. (2009) Prolonged Methylphenidate Treatment Alters the Behavioral Diurnal Activity Pattern of Adult Male Sprague-Dawley Rats. Pharmacology Biochemistry Behavior, 92, 93-99. http://dx.doi.org/10.1016/j.pbb.2008.10.021

[24] Gaytan, O., Lewis, C., Swann, A. and Dafny, N. (1999) Diurnal Differences in Amphetamine Sensitization. European Journal of Pharmacology, 374, 1-9. http://dx.doi.org/10.1016/S0014-2999(99)00243-5

[25] Yang, P., Beasley, A., Eckermann, K., Swann, A. and Dafny, N. (2000) Valproate Prevents the Induction of Sensitization to Methylphenidate (Ritalin) in Rats. Brain Research, 887, 276-284. http://dx.doi.org/10.1016/S0006-8993(00)02996-6

[26] Gaytan, O., Swann, A. and Dafny, N. (1998) Diurnal Differences in Rat's Motor Response to Amphetamine. European Journal of Pharmacology, 345, 119-128. http://dx.doi.org/10.1016/S0014-2999(97)01558-6

[27] Zhang, C.L., Feng, Z.J., Liu, Y., Ji, X.H., Peng, J.Y., Zhang, X.H., Zhen, X.C. and Li, B.M. (2012) Methylphenidate Enhances NMDA-Receptor Response in Medial Prefrontal Cortex via Sigma-1 Receptor: A Novel Mechanism for Methylphenidate Action. PLoS ONE, 12, e51910. http://dx.doi.org/10.1371/journal.pone.0051910

[28] Cone, E.J. (1995) Pharmacokinetics and Pharmacodynamics of Cocaine. Journal of Analytical Toxicology, 19, 459-478. http://dx.doi.org/10.1093/jat/19.6.459

[29] Kuczenski, R. and Segal, D.S. (1999) Sensitization of Amphetamine-Induced Stereotyped Behaviors during the Acute Response. Journal of Pharmacology and Experimental Therapeutics, 288, 699-709.

[30] Dafny, N. and Yang, P.B. (2006) The Role of Age, Genotype, Sex, and Route of Acute and Chronic Administration of 
Methylphenidate: A Review of Its Locomotor Effects. Brain Research Bulletin, 68, 393-405.

http://dx.doi.org/10.1016/j.brainresbull.2005.10.005

[31] Hoffman, B.B., Lefkowitz, R.J., Hardman, J.G., Limbird, L.E., Ruddon, R.W. and Gilman, A.D. (1996) Catecholamines and Sympathomimetic Drugs, and Adrenergic Receptor-Antagonist. Goodman and Gilman's, 1996. The Pharmacological Basis of Therapeutics, 64, 199-250.

[32] Patrick, K.S. and Markowitz, J.S. (1997) Pharmacology of Methylphenidate, Amphetamine Enantiomers, and Pemoline in Attention Deficit/Hyperactivity Disorder. Human Psychopharmacology, 12, 527-546.

[33] Salinas, A.G., Nguyen, C.T., Ahmadi-Tehrani, D. and Morrisett, R.A. (2012) Reduced Ethanol Consumption and Preference in Cocaine- and Amphetamine-Regulated Transcript (CART) Knockout Mice. Addiction Biology, 24, 175-184.

[34] Challman, T.D. and Lipsky, J.J. (2000) Methylphenidate: Its Pharmacology and Uses. Mayo Clinic Proceedings, 75, 711-721. http://dx.doi.org/10.1016/S0025-6196(11)64618-1

[35] Jaffe, S.L. (1991) Intranasal Abuse of Prescribed Methylphenidate by an Alcohol and Drug Abusing Adolescent with ADHD. Journal of American Academy of Child and Adolescent Psychiatry, 30, 773-775.

[36] Kollins, S.H. (2003) Comparing the Abuse Potential of Methylphenidate versus Other Stimulants: A Review of Available Evidence and Relevance to the ADHD Patient. Journal of Clinical Psychiatry, 64, 14-18.

[37] Lee, M.J., Yang, P.B., Wilcox, V.T., Burau, K.D., Swann, A.C. and Dafny, N. (2009) Does Repetitive Ritalin Injection Produce Long-Term Effects on SD Female Adolescent Rats? Neuropharmacology, 57, 201-207. http://dx.doi.org/10.1016/j.neuropharm.2009.06.008

[38] Patrick, K.S., Straughn, A.B., Reeves 3rd, O.T., Bernstein, H., Bell, G.H., Anderson, E.R. and Malcolm, R.J. (2013) Drug Metabolism Disposition, 41, 197-205. http://dx.doi.org/10.1124/dmd.112.048595

[39] Wolf, M.E. (1998) The Role of Excitatory Amino Acids in Behavioral Sensitization to Psychomotor Stimulants. Progress in Neurobiology, 54, 679-720. http://dx.doi.org/10.1016/S0301-0082(97)00090-7

[40] Bell, G.H., Griffin 3rd, W.C. and Patrick, K.S. (2011) Oral and Transdermal DL-Methylphenidate-Ethanol Interactions in C57BL/6J Mice: Potentiation of Locomotor Activity with Oral Delivery. Pharmacology Biochemistry and Behavior, 100, 264-270. http://dx.doi.org/10.1016/j.pbb.2011.08.026

[41] Vendruscolo, L.F., Izidio, G.S., Takahashi, R.N. and Ramos, A. (2008) Chronic Methylphenidate Treatment during Adolescence Increases Anxiety-Related Behaviors and Ethanol Drinking in Adult Spontaneously Hypertensive Rats. Behavioral Pharmacology, 19, 21-27. http://dx.doi.org/10.1097/FBP.0b013e3282f3cfbe

[42] Soeters, H.S., Howells, F.M. and Russell, V.A. (2008) Methylphenidate Does Not Increase Ethanol Consumption in a Rat Model for Attention-Deficit Hyperactivity Disorder: The Spontaneously Hypertensive Rat. Metabolic Brain Disease, 23, 303-314. http://dx.doi.org/10.1007/s11011-008-9098-1

[43] Volkow, N.D., Wang, G.J., Fowler, J.S. and Ding, Y.S. (2005) Imaging the Effects of Methylphenidate on Brain Dopamine: New Model on Its Therapeutic Actions for Attention-Deficit/Hyperactivity Disorder. Biological Psychiatry, 57, 1410-1415. http://dx.doi.org/10.1016/j.biopsych.2004.11.006

[44] Volkow, N.D., G.J., Wang, F., Telang, J.S., Fowler, J., Logan, M., Jayne, Y., Ma, Pradhan, K. and Wong, C. (2007) Profound Decreases in Dopamine Release in Striatum in Detoxified Alcoholics: Possible Orbitofrontal Involvement. Journal of Neuroscience, 27, 12700-12706. http://dx.doi.org/10.1523/JNEUROSCI.3371-07.2007

[45] Markowitz, J.S., DeVane, C.L., Boulton, D.W., Nahas, Z., Risch, S.C., Diamond, F. and Patrick, K.S. (2000) Ethylphenidate Formation in Human Subjects after the Administration of a Single Dose of Methylphenidate and Ethanol. Drug Metabolism and Disposition, 28, 620-624.

[46] Williard, R.L., Middaugh, L.D., Zhu, H.J. and Patrick, K.S. (2007) Methylphenidate and Its Ethanol Transesterification Metabolite Ethylphenidate: Brain Disposition, Monoamine Transporters and Motor Activity. Behavioral Pharmacology, 18, 39-51. http://dx.doi.org/10.1097/FBP.0b013e3280143226

[47] Weight, F.F., Lovinger, D.M. and White, G. (1991) Alcohol Inhibition of NMDA Channel Function. Alcohol and Alcoholism-Supplements, 1, 163-169.

[48] Imperato, A., Honroe, T. and Jensen, L.H. (1990) Dopamine Release in the Nucleus Accumbens Is under Glutamatergic Control through Non-NMDA Receptors: A Study in Freely-Moving Rats. Brain Research, 530, 223-228. http://dx.doi.org/10.1016/0006-8993(90)91286-P

[49] Kalivas, P.W., Sorg, B.A. and Hooks, S.M. (1993) The Pharmacology and Neural Circuitry of Sensitization to Psychostimulants. Behavioural Pharmacology, 4, 315-334. http://dx.doi.org/10.1097/00008877-199308000-00005

[50] Kalivas, P.W., Pierce, R.C., Cornish, J. and Sorg, B.A. (1998) A Role of Sensitization in Craving and Relapse in Cocaine Addiction. Journal of Psychopharmacology, 12, 49-53. http://dx.doi.org/10.1177/026988119801200107

[51] Kalivas, P.W. and Stewart, J. (1991) Dopamine Transmission in the Initiation and Expression of Drug- and Stress-Induced Sensitization of Motor Activity. Brain Research Reviews, 16, 233-244. 
http://dx.doi.org/10.1016/0165-0173(91)90007-U

[52] Wanchoo, S.J., Lee, M.J., Swann, A.C. and Dafny, N. (2010) Bilateral Six-Hydroxydopamine Administration to PFC Prevents the Expression of Behavioral Sensitization to Methylphenidate. Brain Research, 1312, 80-100. http://dx.doi.org/10.1016/j.brainres.2009.11.035

[53] Kalivas, P.W. (2005) A Role of Glutamate Transmission in Addiction to Psychostimulants. Addiction Biology, 5, 325329. http://dx.doi.org/10.1111/j.1369-1600.2000.tb00199.x

[54] Prieto-Gómez, B., Vázquez-Alvarez, A.M., Martínez-Peña, J.L., Reyes-Vázuez, C., Yang, P.B. and Dafny, N. (2005) Methylphenidate and Amphetamine Modulate Differently the NMDA and AMPA Glutaminergic Transmission of Dopaminergic Neurons in the Ventral Tegmental Area. Life Sciences, 77, 635-649. http://dx.doi.org/10.1016/j.lfs.2004.10.076

[55] Wanchoo, S.J., Swann, A.C. and Dafny, N. (2009) Descending Glutamatergic Pathways of PFC Are Involved in Acute and Chronic Action of Methylphenidate. Brain Research, 1301, 68-79. http://dx.doi.org/10.1016/j.brainres.2009.08.095

[56] Martin-Fardon, R., Strong, E.M. and Weiss, F. (2012) Effect of $\sigma_{1}$ Receptor Antagonism on Ethanol and Natural Reward Seeking. Neuroreport, 23, 809-813. http://dx.doi.org/10.1097/WNR.0b013e32835717c8

[57] Adriani, W., Leo, D., Guarino, M., Natoli, A., Di Consiglio, E., De Angelis, G., Traina, E., Testai, E., Perrone-Capano, C. and Laviola, G. (2006) Short-Term Effects of Adolescent Methylphenidate Exposure on Brain Striatal Gene Expression and Sexual/Endocrine Parameters in Male Rats. Annals of the New York Academy of Sciences, 1074, 52-73. http://dx.doi.org/10.1196/annals.1369.005

[58] Santhakumar, V.M., Wallner, M. and Otis, T.S. (2007) Ethanol Acts Directly on Extrasynaptic Subtypes of GABAA Receptors to Increase Tonic Inhibition. Alcohol, 41, 211-221.

[59] Vizi, E.S., Fekete, A., Karoly, M. and Mike, A. (2010) Non-Synaptic Receptors and Transporters Involved in Brain Functions and Targets of Drug Treatment. British Journal of Pharmacology, 160, 785-809. http://dx.doi.org/10.1111/j.1476-5381.2009.00624.x 
Scientific Research Publishing (SCIRP) is one of the largest Open Access journal publishers. It is currently publishing more than 200 open access, online, peer-reviewed journals covering a wide range of academic disciplines. SCIRP serves the worldwide academic communities and contributes to the progress and application of science with its publication.

Other selected journals from SCIRP are listed as below. Submit your manuscript to us via either submit@scirp.org or Online Submission Portal.
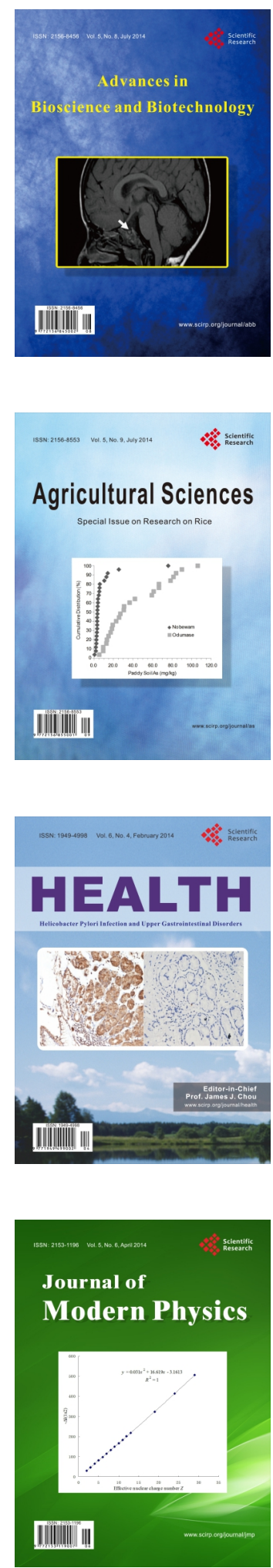
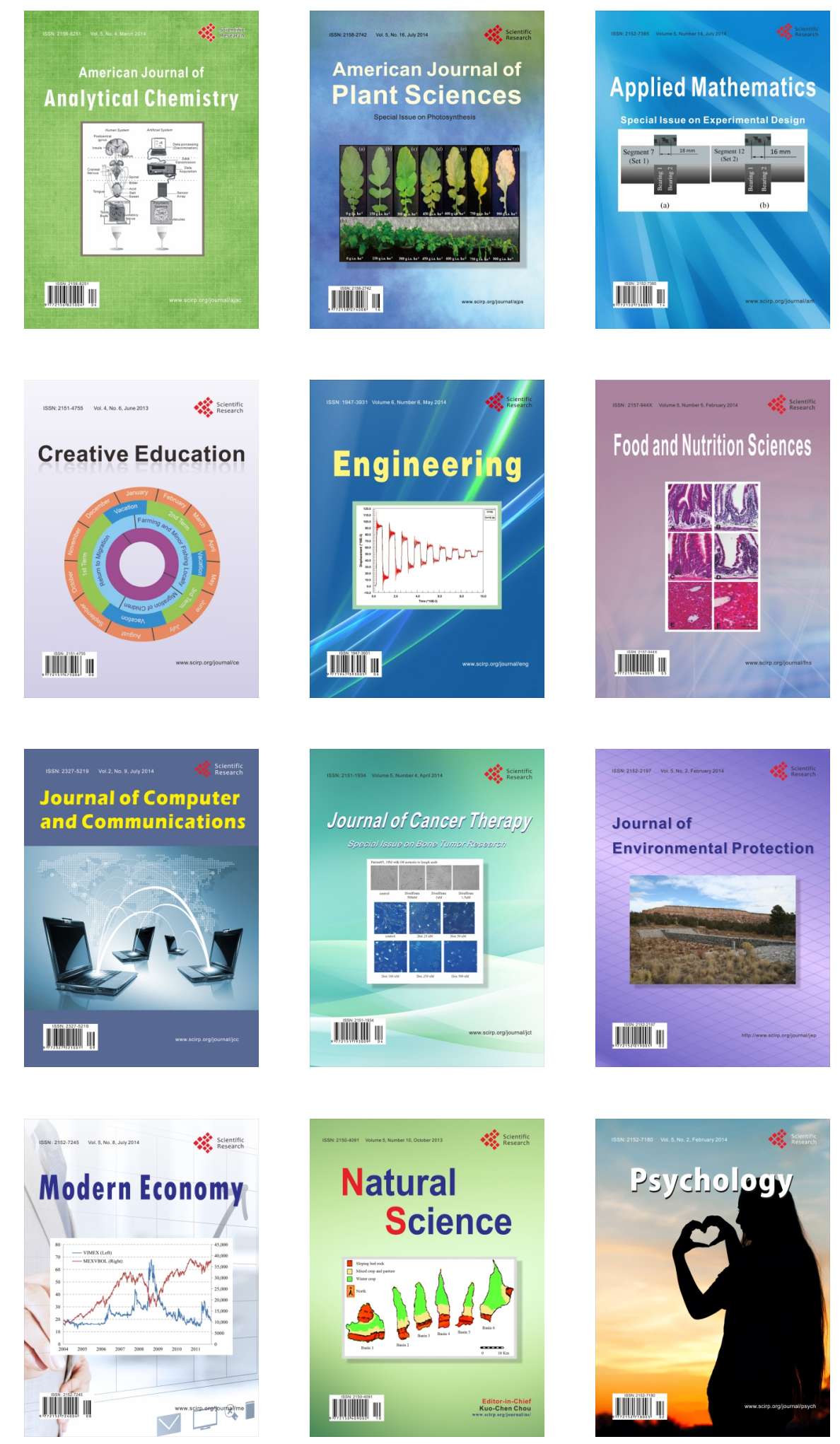